\title{
AVALIAÇÃO DO ESTRESSE HÍDRICO SUBTERRÂNEO DAS BACIAS HIDROGRÁFICAS DOS RIOS PIRACICABA, CAPIVARI E JUNDIAÍ (PCJ)
}

Flavio de PAULA E SILVA

Tiago Vier FISCHER

Sibele EZAKI

Didier GASTMANS

Vinícius Rosa RODRIGUES

José Luiz ALBUQUERQUE FILHO

Andrea Segura FRANZINI

Julia Octaviano NOALE

\section{RESUMO}

Este artigo apresenta uma avaliação do nível de estresse hídrico subterrâneo dos aquíferos presentes nas bacias dos rios Piracicaba, Capivari e Jundiaí, localizadas no sudeste do Brasil, distribuídos por $15.378 \mathrm{~km}^{2}$, dos quais $92,5 \%$ pertencem ao Estado de São Paulo e uma pequena parte (7,5\%) ao Estado de Minas Gerais. A avaliação do estresse hídrico dos aquíferos é baseada em indicadores de consumo e de disponibilidade. $\mathrm{O}$ indicador de consumo utilizado foi a intensidade de explotação, estimada com aplicação da ferramenta de geoprocessamento Kernel Density, com utilização de 11.621 dados de vazões de poços obtidas do cadastro de outorgas do Departamento de Águas e Energia Elétrica - DAEE, complementadas com dados da porção mineira da bacia, extraídos do cadastro CPRM - Serviço Geológico do Brasil. O indicador de disponibilidade utilizou dados de vazão mínima $\mathrm{Q}_{95}$ da porção paulista das Bacias PCJ, calculados a partir dos estudos de regionalização hidrológica realizados pelo DAEE. Aplicando-se o método de geoprocessamento de subtração dos grids dos mapas de disponibilidade hídrica e de intensidade de explotação, obteve-se o mapa de estresse hídrico, expresso em termos de saldo hídrico. O mapa de estresse distingue áreas com déficit hídrico (saldo negativo) de áreas com excedente hídrico (saldo positivo), em termos de vazão anual disponível $\left(\mathrm{m}^{3} / \mathrm{ano}\right)$. O método mostrou-se eficiente na identificação de áreas com déficit hídrico, possibilitando o direcionamento dos esforços de gestão no monitoramento e aplicação de diretrizes de utilização e proteção.

Palavras-chave: Estresse hídrico; Bacias PCJ; Gestão; Hidrogeologia.

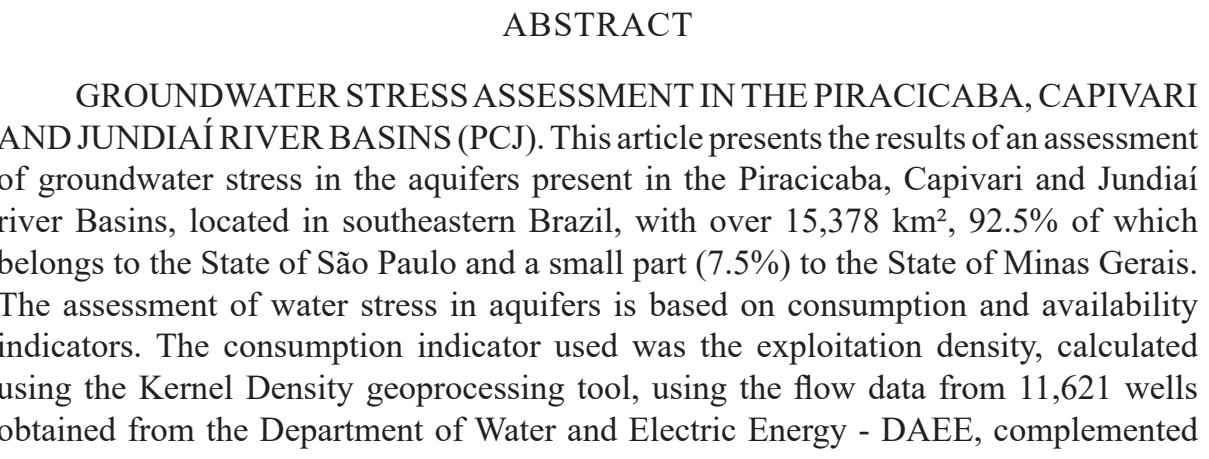


with data from Minas Gerais State, extracted from the CPRM - Geological Survey of Brazil database. The availability indicator used the $\mathrm{Q}_{95}$ minimum flow rate, calculated from the hydrological regionalization studies carried out by DAEE. Applying the geoprocessing method of subtracting the grids from the water availability and exploitation intensity maps, the water stress map was obtained, expressed in terms of water balance. The stress map discriminates areas with water deficit (negative balance) from areas with water overplus (positive balance), in terms of available annual flow rate $\left(\mathrm{m}^{3} /\right.$ year). The method proved to be efficient in the identification of areas with water deficit, making it possible to direct management efforts to monitor and apply usage and protection guidelines.

Keywords: Water stress; PCJ Basins; Management; Hydrogeology.

\section{INTRODUÇÃO}

As bacias dos rios Piracicaba, Capivari e Jundiaí (Bacias PCJ) estendem-se pelos estados de São Paulo e Minas Gerais e compreendem um recorte territorial de regiões hidrográficas do sudeste brasileiro. Abrangem território de $15.378 \mathrm{~km}^{2} \mathrm{e}$ subdividem-se em 7 sub-bacias principais (Figura 1), assim ordenadas de acordo com sua representatividade em área: Piracicaba $\left(3.776 \mathrm{~km}^{2}\right)$, Jaguari $\left(3.304 \mathrm{~km}^{2}\right)$, Atibaia $\left(2.816 \mathrm{~km}^{2}\right)$, Corumbataí $\left(1.719 \mathrm{~km}^{2}\right)$, Capivari $\left(1.568 \mathrm{~km}^{2}\right)$, Jundiaí $(1.155$ $\left.\mathrm{km}^{2}\right)$ e Camanducaia $\left(1.040 \mathrm{~km}^{2}\right)$.

A maior parte do território das Bacias PCJ (92,5\%) encontra-se no Estado de São Paulo $\left(14.217 \mathrm{~km}^{2}\right)$ e uma pequena parte $(7,5 \%)$ no de Minas Gerais $\left(1.161 \mathrm{~km}^{2}\right)$. Inseridos total ou parcialmente nessa unidade de gestão encontram-se 71 municípios paulistas e 5 municípios mineiros, cuja população é de cerca de 6 milhões de pessoas (IBGE 2010). Essa grande população, aliada a níveis elevados de atividade econômica, que respondem por cerca de 5\% do PIB (Produto Interno Bruto) brasileiro e 14\% do PIB do Estado de São Paulo, requer demanda considerável e crescente de recursos hídricos, sejam superficiais ou subterrâneos.

Nas Bacias PCJ, as águas subterrâneas extraídas majoritariamente dos aquíferos Tubarão e Cristalino são utilizadas, preponderantemente, para abastecimento público e industrial e são de importância fundamental para manutenção do escoamento de base dos cursos superficiais (PROFILL-RHAMA 2018).

Uma das principais ferramentas de gestão de recursos hídricos subterrâneos é a avaliação do estresse hídrico dos aquíferos. Também denominado de escassez hídrica física, esse termo é utilizado para designar uma situação em que a demanda por água é maior do que a sua quantidade disponível para uso e/ou capacidade de renovação (RICHEY et al. 2005, GLEESON \& WADA 2013). A avaliação do estresse hídrico dos aquíferos é um procedimento baseado na relação entre consumo e oferta de água subterrânea, que visa identificar regiões com acentuada redução das disponibilidades ou mesmo com déficit, em um cenário de comprometimento da sustentabilidade do recurso, que pode afetar significativamente a economia e o ecossistema da bacia. Nesse sentido, o estresse hídrico atesta em que grau a capacidade hídrica dos aquíferos está sendo afetada, ou seja, se há equilíbrio entre disponibilidade e demanda de água subterrânea ou, caso contrário, qual a magnitude ou severidade do desequilíbrio. Essa informação constitui um dos passos mais importantes para a gestão dos recursos hídricos subterrâneos, uma vez que aponta áreas nas quais há necessidade de intervenção por parte dos órgãos gestores, no sentido de aplicar políticas públicas para preservação e manutenção dos recursos hídricos subterrâneos.

As disponibilidades hídricas subterrâneas compreendem uma parcela das reservas subterrâneas totais que pode ser extraída anualmente do armazenamento dos aquíferos durante um período de tempo planejado, de modo a não causar impactos ambientais, econômicos e sociais graves. A definição da parcela explotável ou disponibilidade dos aquíferos contempla tanto aspectos técnicos como políticos e tem como objetivo o uso sustentável dos recursos hídricos subterrâneos, tendo em vista o seu aproveitamento racional, manutenção da qualidade das águas e manutenção do escoamento de base dos rios.

No estado de São Paulo, as disponibilidades hídricas subterrâneas são estimadas com base na 

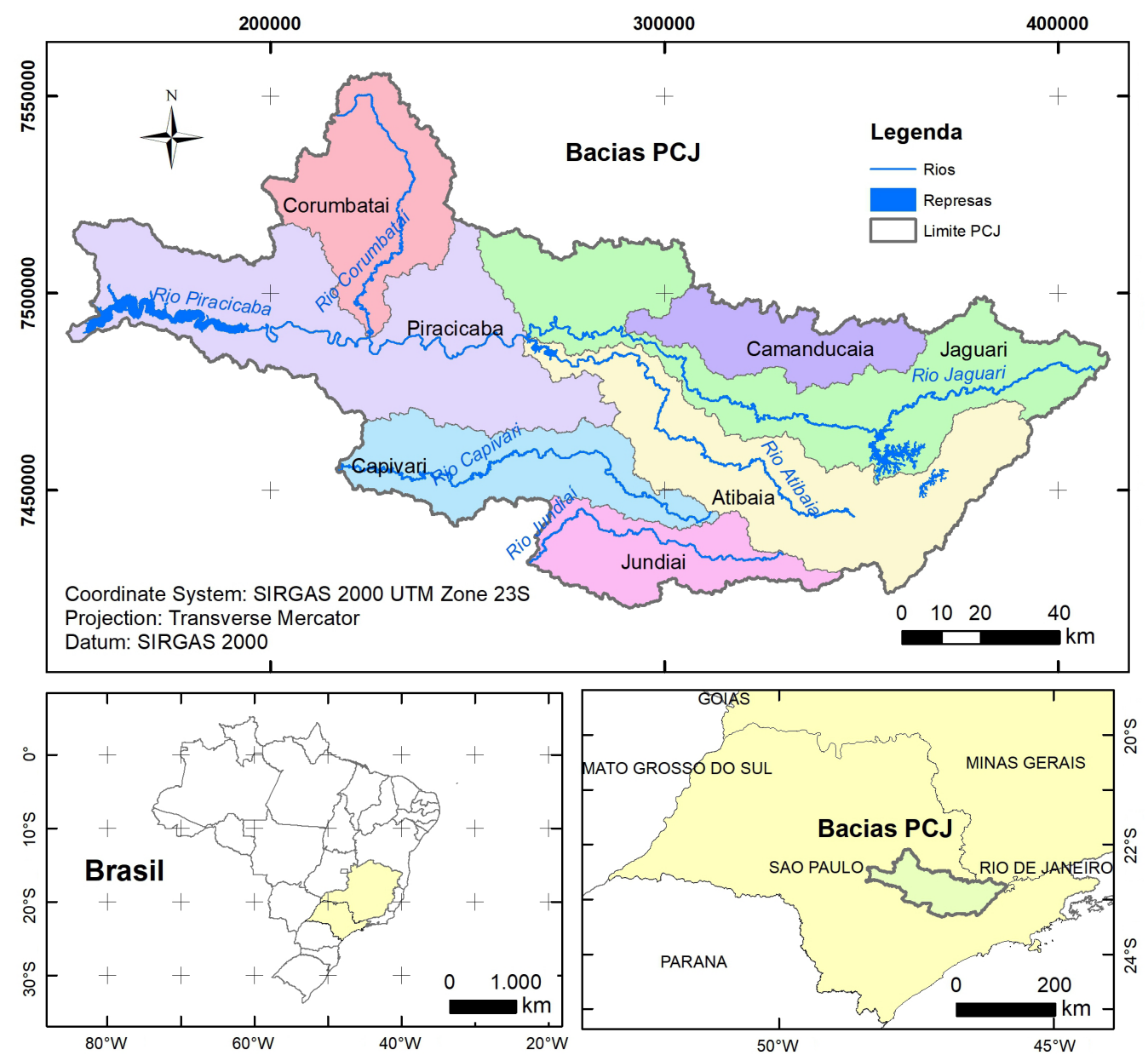

FIGURA 1 - Mapa de localização das Bacias PCJ.

vazão mínima de permanência com frequência de $95 \%$ do tempo $\left(\mathrm{Q}_{95}\right)$, definida por meio de estudos hidrológicos realizados pelo DAEE em décadas passadas. Com base nesses dados, DAEE/ UNESP (2013) classificou as disponibilidades hídricas específicas do Estado em três faixas: (i) baixa - de $2,30 \mathrm{~L} / \mathrm{s} / \mathrm{km}^{2}$ a $3,81 \mathrm{~L} / \mathrm{s} / \mathrm{km}^{2}$, no extremo oeste; (ii) média - de $2,46 \mathrm{~L} / \mathrm{s} / \mathrm{km}^{2}$ a $5,05 \mathrm{~L} / \mathrm{s} /$ $\mathrm{km}^{2}$, na região central do Estado; (iii) alta - de $5,05 \mathrm{~L} / \mathrm{s} / \mathrm{km}^{2}$ a $21,29 \mathrm{~L} / \mathrm{s} / \mathrm{km}^{2}$, no extremo leste do Estado. Já na porção mineira da bacia ainda não foram elaborados estudos específicos sobre as disponibilidades hídricas subterrâneas.

As vazões extraídas por meio de poços constituem o indicador de consumo e contempla todos os usos consuntivos da bacia. Embora a densidade de poços também seja um indicador importante para avaliação do estresse, o maior impacto sobre as reservas hídricas dos aquíferos é provocado pela quantidade de água extraída (vazão) pelo bombea- mento de poços. Nesse sentido, áreas com grande concentração de poços, que extraem importantes volumes de água são potencialmente impactantes para os aquíferos e prioritárias para instalação de sistemas de monitoramento para controle de retiradas e da qualidade das águas subterrâneas.

Usualmente, a avaliação do estresse hídrico subterrâneo nos estudos hidrogeológicos e planos de bacias - conceituada como balanço hídrico subterrâneo - utiliza como unidade de gestão bacias ou sub-bacias hidrográficas, cujas dimensões superficiais afetam diretamente o cálculo das disponibilidades. Nesse sentido, bacias com grandes dimensões normalmente resultam numa avaliação de estresse hídrico modesto, mesmo tendo uma extração significativa de água dos aquíferos; por outro lado, bacias de pequenas dimensões normalmente são classificadas como de elevado estresse hídrico, mesmo com pequena extração de água. Essa situação não distingue as 
porções ou regiões dos aquíferos efetivamente estressadas.

Ao contrário, a utilização de um método simples de geoprocessamento no tratamento de indicadores de disponibilidade hídrica e de consumo, como aqui mostrado, permite identificar e avaliar adequadamente o nível de estresse hídrico dos aquíferos ou porções deles, proporcionando melhores resultados quando comparado com os métodos usualmente aplicados. Esse método foi empregado no Plano de Monitoramento Quali-quantitativo das Águas Subterrâneas das Bacias PCJ (PROFILL 2019) com excelente resultado. Com base numa reavaliação dos dados utilizados no citado projeto, os resultados aqui apresentados demostram sua efetividade na identificação de áreas estressadas e destacam a importância do método como ferramenta relevante para a gestão de recursos hídricos subterrâneos.

\section{MATERIAIS E MÉTODO}

O estresse hídrico pode ser avaliado pelo saldo hídrico, que compreende a diferença entre os volumes de água subterrânea disponíveis para uso (indicadores de disponibilidade) e os volumes extraídos por poços (indicadores de consumo), ou seja, quanto resta de água à disposição dos usuários, considerando a sustentabilidade dos sistemas aquíferos.
$\mathrm{O}$ indicador de consumo utilizado foi a intensidade de explotação dos aquíferos, calculada com base em 11.621 dados de vazões de poços, dos quais 11.611 foram obtidos no cadastro de outorgas de águas subterrâneas do DAEE, ano base 2018, e 10 poços do cadastro Sistema de Informações de Águas Subterrâneas - SIAGAS do Serviço Geológico do Brasil - CPRM, uma vez que não se teve acesso ao cadastro de outorgas do Instituto Mineiro de Gestão das Águas - IGAM (Figura 2).

Os níveis de intensidade de explotação foram representados em mapa de densidade de vazões anuais extraídas, elaborado com emprego da ferramenta de geoprocessamento Kernel Density. A função Kernel gera uma superfície de interpolação bidimensional suave, que é proporcional à intensidade dos valores pontuais das amostras e dependente do raio de busca. No método Kernel define-se uma vizinhança circular em torno de cada ponto da amostra e a ferramenta de geoprocessamento aplica, automaticamente, uma função $\mathrm{k}$ normal que atribui pesos variando de 1 , no local do ponto, a 0 no limite da vizinhança (PÔSSA 2014). Os parâmetros considerados nesta análise espacial foram grid de saída regular de $500 \mathrm{~m}$, raio de pesquisa de $5 \mathrm{~km}$ e campo de população igual à vazão outorgada $\left(\mathrm{m}^{3} / \mathrm{ano}\right)$.

$\mathrm{O}$ indicador de disponibilidade hídrica subterrânea utilizado foi a vazão mínima de referência

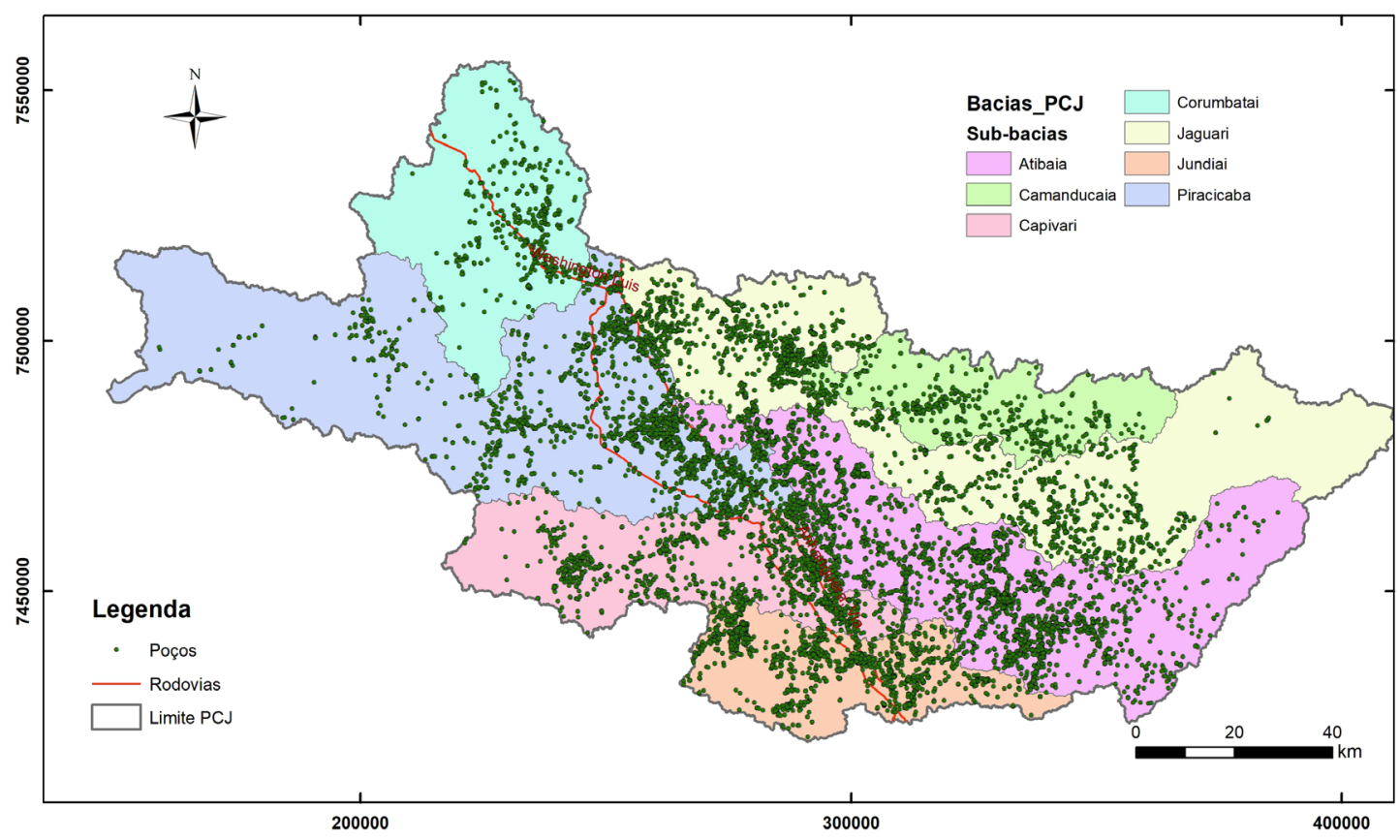

FIGURA 2 - Distribuição dos poços utilizados na estimativa de consumo de água subterrânea. 
$\mathrm{Q}_{95}$, que corresponde à vazão mínima superficial de permanência com frequência de $95 \%$ do tempo na bacia hidrográfica. A vazão mínima $\mathrm{Q}_{95}$ costuma ser adotada pelo DAEE (DAEE/UNESP 2013) como referência de disponibilidade hídrica subterrânea nos relatórios de situação de recursos hídricos estaduais e foi considerada, neste estudo, como aproximadamente equivalente à recarga sazonal dos aquíferos.

Os dados de vazão mínima Q95 da porção paulista das Bacias PCJ foram obtidos de arquivos do projeto Atlas de Águas Subterrâneas do Estado de São Paulo (DAEE/UNESP 2013). Essas vazões mínimas foram calculadas a partir dos estudos de regionalização hidrológica, realizados pelo DAEE, para 70 microbacias paulistas integrantes das Bacias PCJ. As contribuições unitárias da $\mathrm{Q}_{95}$ dessas microbacias variam de $3,34 \mathrm{~L} / \mathrm{s} / \mathrm{km}^{2}$ a $5,49 \mathrm{~L} / \mathrm{s} / \mathrm{km}^{2}$ (Figura 3). Na ausência de estudos hidrológicos, para a porção mineira da bacia foi considerado o valor de $4,52 \mathrm{~L} / \mathrm{s} / \mathrm{km}^{2}$ para a contribuição unitária da vazão $Q_{95}$, estimado pela média da bacia do Rio Jaguari, adotada como referência por conter a maior parte da área de Minas Gerais (PROFILL-RHAMA 2018). As vazões $Q_{95}$ foram convertidas, posteriormente, para $\mathrm{m}^{3} / \mathrm{ano} / \mathrm{km}^{2}$ para os cálculos do estresse hídrico.

\section{ARCABOUÇO HIDROGEOLÓGICO DAS BACIAS PCJ}

As águas subterrâneas da Bacia PCJ estão armazenadas em reservatórios de porosidade granular e fissural contidos nas formações geológicas, discriminados em termos de sistemas aquíferos com base em suas características litológicas e de permoporosidade.

Dois domínios hidrogeológicos principais são distinguidos nas Bacias PCJ: o domínio de porosidade fissural predominante, representado pelos sistemas aquíferos Cristalino e Serra Geral, com área de ocorrência em superfície de $7.868 \mathrm{~km}^{2}$; e o domínio de porosidade predominante granular, representado pelos sistemas aquíferos integrantes da Bacia do Paraná - Tubarão, Guarani, Itaqueri e Rio Claro - e coberturas cenozoicas indiferenciadas, com área de ocorrência de $7.509 \mathrm{~km}^{2}$ (Quadro 1 e Figura 4). Destaca-se, ainda, o conjunto de rochas predominantemente pelíticas e praticamente impermeáveis, constituintes do Aquitardo Passa Dois, que cobre área de $1.185 \mathrm{~km}^{2}$.

Os sistemas aquíferos são abastecidos direta e continuamente por águas pluviais que se infiltram nas formações geológicas e formam os reservatórios subterrâneos. Nas Bacias PCJ, os terrenos recebem precipitações médias plurianuais que variam de $1.195 \mathrm{~mm}$ a pouco mais de $1.600 \mathrm{~mm}$ anuais, com precipitações mais intensas no extremo leste, na região da Serra da Mantiqueira, e menores

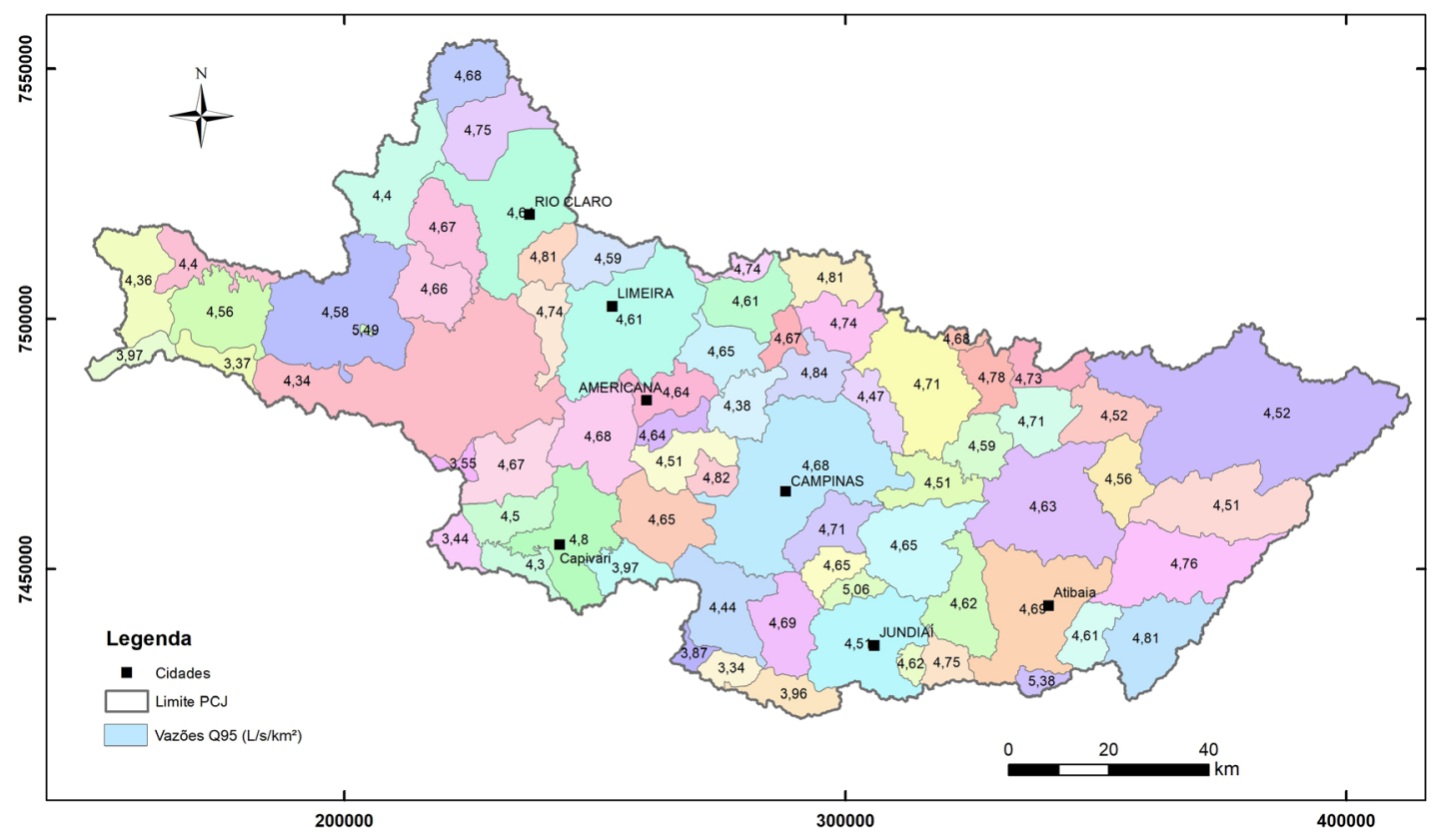

FIGURA 3 - Vazões mínimas $\mathrm{Q}_{95}\left(\mathrm{~L} / \mathrm{s} / \mathrm{km}^{2}\right)$ das Bacias PCJ. 
QUADRO 1 - Sistemas Aquíferos das Bacias PCJ.

\begin{tabular}{cllll}
\hline $\begin{array}{c}\text { Unidades } \\
\text { litoestratigráficas }\end{array}$ & Sistemas Aquiferos & Tipo & $\begin{array}{c}\text { Área } \\
\left(\mathrm{km}^{2}\right)\end{array}$ & $\%$ \\
\hline Aluviões & $\begin{array}{l}\text { Coberturas } \\
\text { indiferenciadas }\end{array}$ & Sedimentar & 513 & $3,3 \%$ \\
\hline Coberturas indiferenciadas & Rio Claro & Sedimentar & 135 & $0,9 \%$ \\
\hline Rio Claro & Itaqueri & Sedimentar & 176 & $1,1 \%$ \\
\hline Itaqueri & Serra Geral & Fissural & 837 & $5,4 \%$ \\
\hline Serra Geral & Guarani & Sedimentar & 2016 & $13,1 \%$ \\
\hline Intrusivas básicas & Passa Dois & Sedimentar & 1185 & $7,7 \%$ \\
\hline Botucatu & Aquitardo regional) & Sedimentar & 3484 & $22,7 \%$ \\
\hline Piramboia & Tubarão & Fissural & 7031 & $45,7 \%$ \\
\hline Corumbatai & Cristalino & &
\end{tabular}

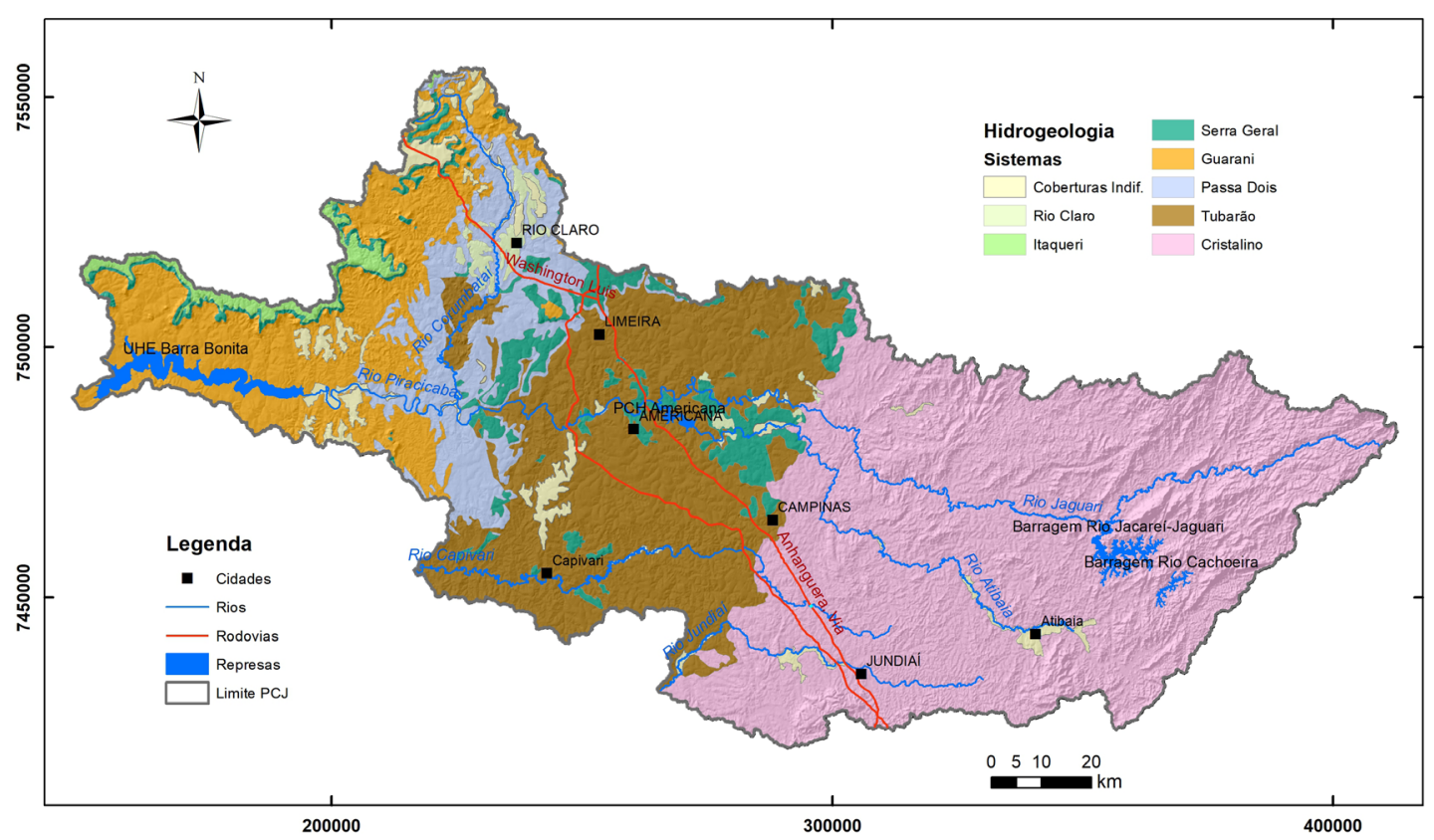

FIGURA 4 - Distribuição dos Sistemas Aquíferos das Bacias PCJ (adaptado de Mapa geológico do Convênio DAEE/UNESP 1980).

na porção centro sul, na região da Depressão Periférica Paulista (PROFILL 2019).

A maior parte da água das precipitações atmosféricas evapora ao atingir o solo; uma pequena parcela se transforma em escoamento superficial das bacias hidrográficas da região; e uma parcela menor infiltra-se no terreno pelas camadas superiores do solo e alcança os aquíferos em profundidade. Para a parte paulista das Bacias PCJ, LIAZI et al. (2007) estimaram, pelo método hidrológico, evapotranspiração em $72 \%$ da precipitação atmos- férica média de $1.382 \mathrm{~mm}$ anuais $\left(442 \mathrm{~m}^{3} / \mathrm{s}\right)$, escoamento superficial em $21 \%\left(129 \mathrm{~m}^{3} / \mathrm{s}\right)$ e recarga dos aquíferos em $7 \%\left(43 \mathrm{~m}^{3} / \mathrm{s}\right)$. A maior parte da recarga corresponde à reserva renovável anual dos aquíferos, que é descarregada para a rede de drenagem das bacias hidrográficas na forma de escoamento de base, em ciclos anuais que se repetem continuamente.

O comportamento do fluxo subterrâneo nos diferentes aquíferos é governado pelas características litológicas do arcabouço (que controlam os pa- 
râmetros hidrodinâmicos condutividade hidráulica, transmissividade, porosidade efetiva e coeficiente de armazenamento), pela natureza (livre, semiconfinado ou confinado) e pela geometria (área de ocorrência e espessura) dos reservatórios.

\section{DETERMINAÇÃO DO ESTRESSE HÍDRICO NAS BACIAS PCJ}

A identificação e avaliação das áreas de estresse hídrico nas Bacias PCJ foi feita a partir do cruzamento dos mapas de intensidade de explotação e de disponibilidade hídrica subterrânea, elaborados conforme descritos no item 2 .

O mapa raster de intensidade de explotação (Figura 5) destaca áreas com elevada concentração de extração de água subterrânea variando de $2,02 \times 10^{4} \mathrm{~m}^{3}$ a $7,37 \times 10^{4} \mathrm{~m}^{3}$ anuais, abrangendo as regiões de montante das bacias dos rios Piracicaba e Capivari, e trecho intermediário da bacia do rio Jundiaí. Essas áreas, com predisposição à conurbação e com intensa extração de águas subterrâneas dos aquíferos locais, formam um corredor principal ao longo das rodovias Anhanguera e Bandeirantes, com cerca de $120 \mathrm{~km}$ de extensão e $20 \mathrm{~km}$ de largura no trecho mais largo. Nesse corredor estão situadas importantes cidades paulistas, como Louveira, Valinhos, Campinas, Nova Odessa, Sumaré, Americana, Piracicaba e Limeira, entre outras. Também são notadas manchas menores de extração concentrada de águas subterrâneas distribuídas irregularmente por áreas mais intensamente urbanizadas, especialmente na região de Capivari. As vazões totais explotadas nas Bacias PCJ foram estimadas em $2,57 \times 10^{8} \mathrm{~m}^{3} /$ ano.

O mapa raster indicador de disponibilidade hídrica subterrânea (Figura 6) mostra a distribuição, por microbacias, das vazões anuais $\left(\mathrm{m}^{3} / \mathrm{ano}\right)$ calculadas a partir dos estudos de regionalização hidrológica com vazões mínimas $\mathrm{Q}_{95}$ realizados pelo DAEE, conforme descrito no item 2. Admitindo-se que essas vazões mínimas sejam equivalentes à recarga sazonal, a quantidade de água que circula anualmente nos aquíferos das Bacias PCJ é da ordem de $2,21 \times 10^{9} \mathrm{~m}^{3}$.

Aplicando-se o método de geoprocessamento de subtração dos grids dos mapas de disponibilidade hídrica (Figura 6) e de intensidade de explotação (Figura 5) tem-se o resultado do estresse hídrico, expresso em termos de saldo hídrico (Figura 7). O mapa de estresse distingue áreas com déficit hídrico (saldo negativo) de áreas com excedente hídrico (saldo positivo), em termos de vazão anual disponível $\left(\mathrm{m}^{3} / \mathrm{ano}\right)$. Para uma avaliação visual do comprometimento dos recursos hídricos subterrâneos, o mapa de estresse inclui uma escala em valores percentuais das disponibilidades hídricas ainda passíveis de utilização, nos diversos compartimentos das Bacias PCJ.

A análise do mapa de estresse hídrico (Figura 7) mostra que há um déficit hídrico no entorno

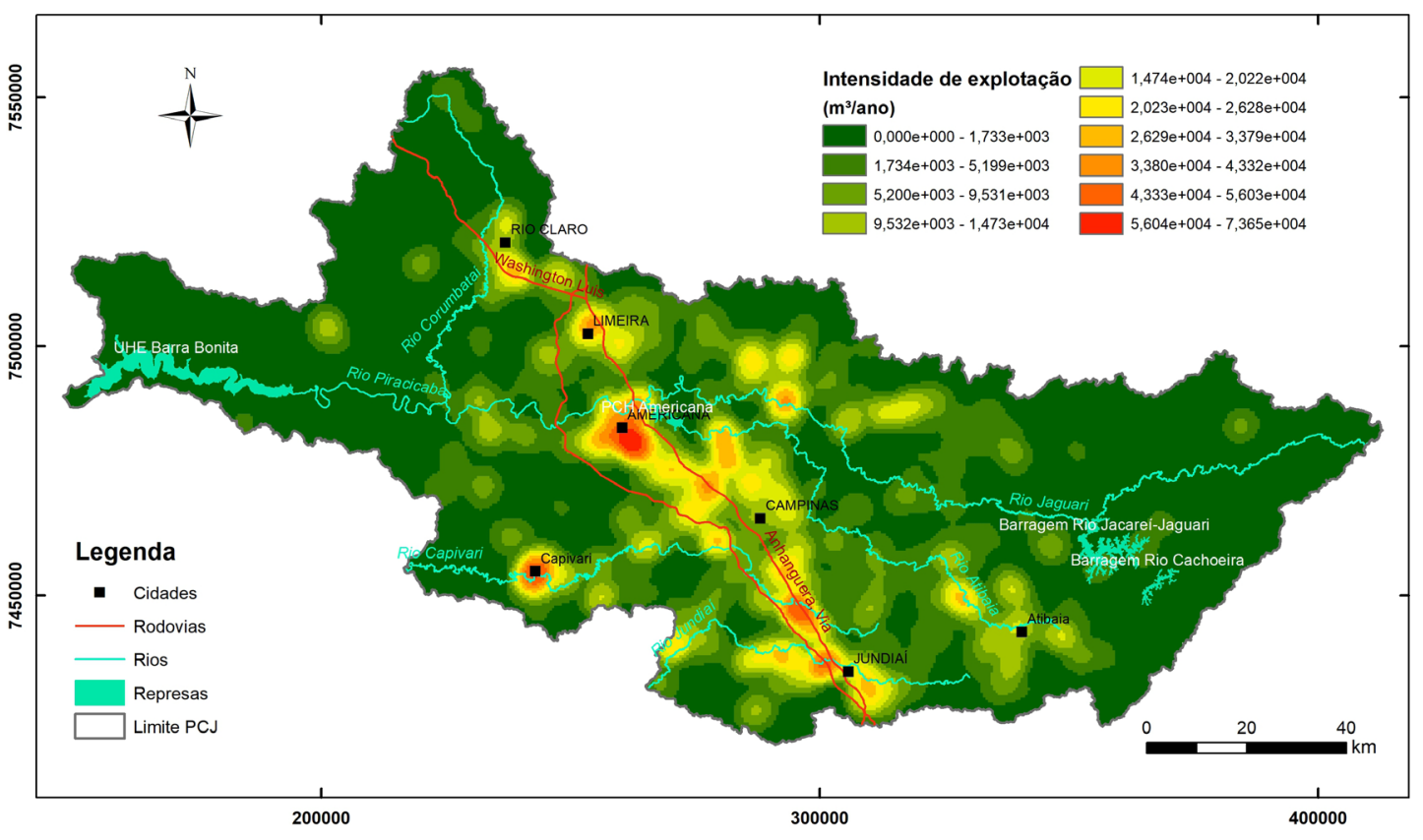

FIGURA 5 - Mapa de intensidade de explotação ( $\left.\mathrm{m}^{3} / \mathrm{ano}\right)$ das Bacias PCJ. 


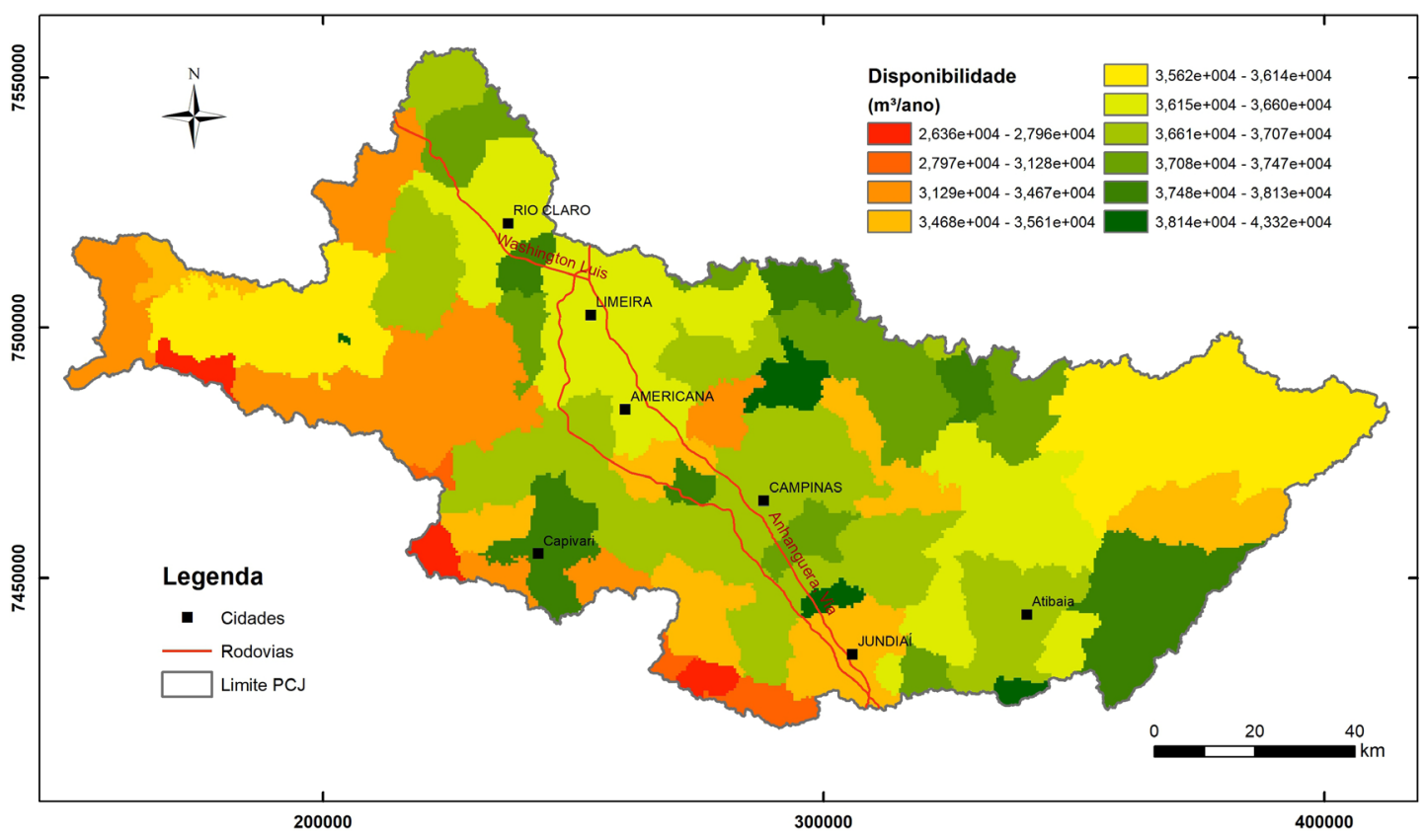

FIGURA 6 - Disponibilidades hídricas subterrâneas (m³/ano) das Bacias PCJ.

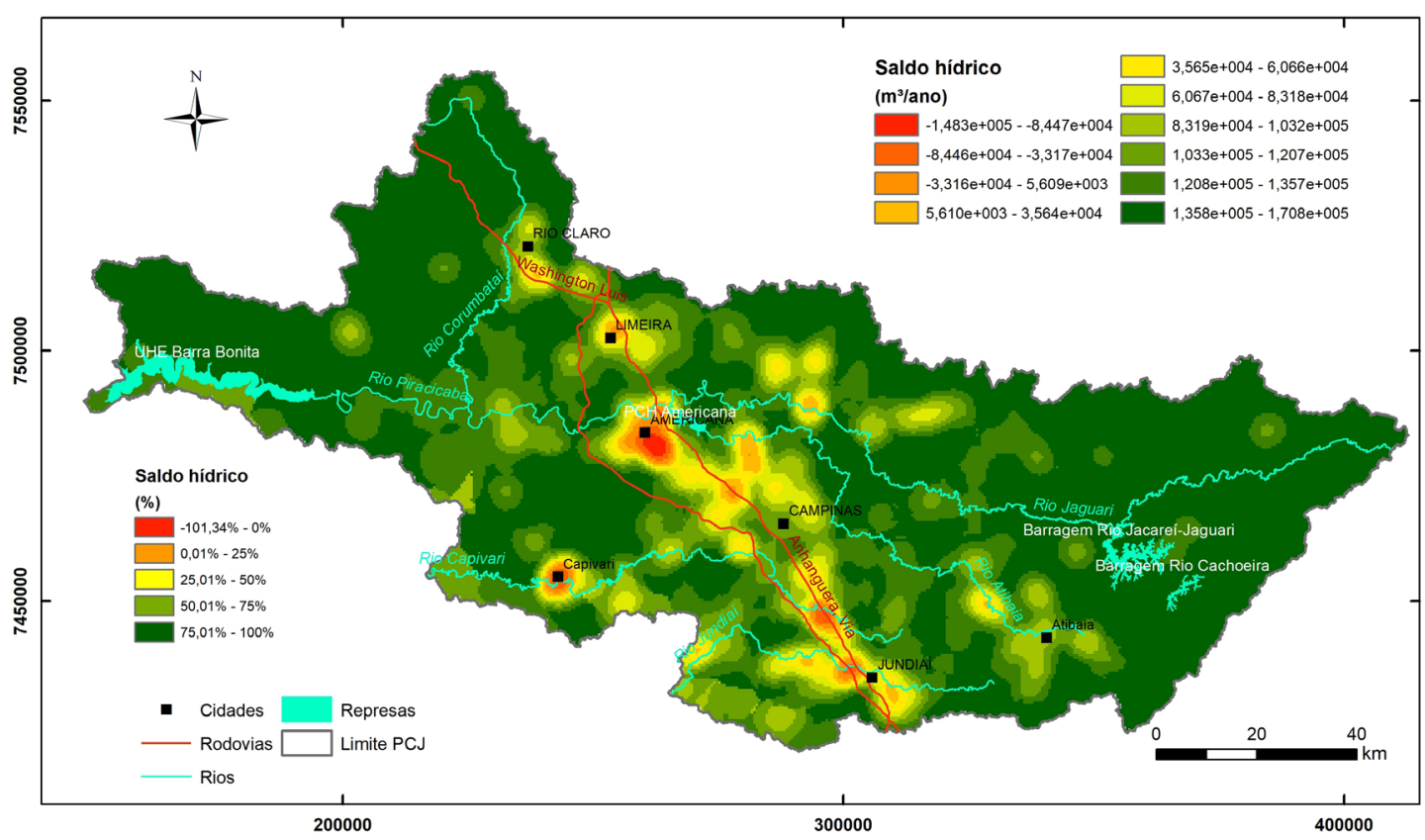

FIGURA 7 - Avaliação do estresse hídrico ( $\mathrm{m}^{3} /$ ano e \%) das Bacias PCJ.

e regiões das cidades de Americana, Campinas, Capivari e Jundiaí, assim como uma redução das disponibilidades ao longo do eixo das rodovias Anhanguera e Bandeirantes, onde se situam municípios com elevado nível de atividade industrial.

Comparado com o método tradicional, que calcula a diferença entre as disponibilidades totais e o consumo total com base numa referência ter- ritorial definida, como por exemplo uma bacia ou sub-bacia, os resultados apresentados distinguem melhor as porções dos aquíferos efetivamente estressadas. No método tradicional, as disponibilidades totais das Bacias PCJ alcançam 2,21 x $10^{9} \mathrm{~m}^{3 /}$ ano, enquanto o consumo atinge $2,57 \times 10^{8} \mathrm{~m}^{3} / \mathrm{ano}$, resultando em excedente hídrico de $1,95 \times 10^{9} \mathrm{~m}^{3 /}$ ano, ou seja, as disponibilidades ainda restantes 
nas bacias representam $88 \%$ do total. Esse cálculo simplista transmite ao gestor a sensação de que as disponibilidades hídricas são suficientemente confortáveis para atender integralmente as demandas de água subterrânea quando, na verdade, não é o que revela o mapa de estresse hídrico.

Diferentemente dos métodos usualmente utilizados para avaliação do estresse hídrico, o método de geoprocessamento empregado neste estudo discrimina as porções do terreno que efetivamente apresentam déficit hídrico, direcionando os esforços de gestão no monitoramento e aplicação de diretrizes de utilização e proteção.

\section{CONCLUSÕES}

O método para determinação do estresse hídrico com utilização da ferramenta de geoprocessamento Kernel Density e emprego de indicadores de disponibilidade e de consumo mostrou-se bastante efetivo na identificação de áreas com elevado déficit hídrico, comparado com métodos tradicionais de avaliação.

A aplicação desse método depende do conhecimento da localização e da vazão extraída pelos poços em operação, condição que exige empenho dos órgãos gestores de recursos hídricos no sentido de cadastrar as captações subterrâneas e de atualizar continuamente o banco de dados de captações. Esse conhecimento permitirá atingir a proficiência necessária para a efetiva aplicação dos instrumentos administrativos previstos nas políticas nacional e estadual de recursos hídricos.

\section{AGRADECIMENTOS}

Aos relatores da revista pelas sugestões que aprimoraram o artigo. E a todos que participaram e contribuíram de alguma forma com o desenvolvimento deste trabalho.

\section{REFERÊNCIAS BIBLIOGRÁFICAS}

DAEE/UNESP - DEPARTAMENTO DE ÁGUAS E ENERGIA ELÉTRICA/ UNIVERSIDADE ESTADUAL PAULISTA. 1980. Mapa geológico do Estado de São Paulo. Escala 1: 250.000. Convênio DAEE/ UNESP, Secretaria de Obras e do Meio Ambiente do Estado de São Paulo, São Paulo.

DAEE/UNESP - DEPARTAMENTO DE ÁGUAS E ENERGIA ELÉTRICA/ UNIVERSIDADE eSTAdUAL PAULiSTA. 2013. Águas subterrâneas do Estado de São Paulo, diretrizes de utilização e proteção. Departamento de Águas e Energia Elétrica (DAEE), Instituto Geociências e Ciências Exatas, Laboratório de Estudo de Bacias (UNESP-LEBAC). Governo do Estado de São Paulo, São Paulo, 44 p. ilus.

GLEESON, T.; WADA, Y. 2013. Assessing regional groundwater stress for nations using multiple data sources with the groundwater footprint. Environmental Research Letters, 8: 044010, 9 p. https://doi.org/10.1088/17489326/8/4/044010

IBGE - INSTITUTO BRASILEIRO DE GEOGRAFIA E ESTATÍSTICA. 2010. Censo Demográfico 2010. Rio de Janeiro, IBGE, 265 p. + CD-ROM. Disponível em https://www.ibge.gov. br/estatisticas/sociais/populacao/9662-censo-demografico-2010.html?=\&t=resultados. Acessado em 1 abr. 2021.

LIAZI, A.; MANCUSO, M.A.; CAMPOS, J.E. 2007. Outorga Integrada: águas superficiais e águas subterrâneas. In: ABRH, SIMPÓSIO BRASILEIRO DE RECURSOS HÍDRICOS, 17, Anais, São Paulo, 17 p.

PÔSSA, E.M. 2014. Análise da densidade de eventos de degradação florestal e desflorestamento e sua relação com os polos madeireiros no estado do Pará. Monografia, Programa de Pós-Graduação em Sensoriamento Remoto, Instituto Nacional de Pesquisas Espaciais, São José dos Campos, 15 p.

PROFILL - PROFILL ENGENHARIA E AMBIENTE S.A. 2019. Plano monitoramento quali-quantitativo das águas subterrâneas das $B a$ cias PCJ. Agência PCJ, Piracicaba, 3 Tomos.

PROFILL-RHAMA. 2018. Primeira Revisão do Plano das Bacias Hidrográficas dos Rios Piracicaba, Capivari e Jundiai - 2010 a 2020. Agência PCJ, Piracicaba, 3 Tomos. (Relatório Final).

RICHEY, A.S.; THOMAS, B.F.; LO, M-H.; REAGER, J.T.; FAMIGLIETTI, J.S.; VOSS, K.; SWENSON, S.; RODELL, M. 2005. Quantifying renewable groundwater stress with GRACE. Water Resource Research, 51: 5217-5238. https://doi. org/10.1002/2015WR017349 


\section{Endereço dos autores:}

Flavio de Paula e Silva - Geodata Consultoria e Projetos Hidrogeológicos, Araraquara, SP, Brasil. E-mail: geodata@fpsgeodata.com.br

Tiago Vier Fischer - Fischer Geologia Ltda., Porto Alegre, RS, Brasil. E-mail: tiago@fischergeologia. com

Sibele Ezaki - Instituto de Pesquisas Ambientais, Secretaria de Infraestrutura e Meio Ambiente/SP, Rua Joaquim Távora, 822, Vila Mariana, CEP: 04015-011, São Paulo, SP, Brasil.E-mail: sibezaki@sp.gov.br

Didier Gastmans - Centro de Estudos Ambientais - CEA, Universidade Estadual Paulista "Júlio de Mesquita Filho" - UNESP, Av. 24A, 1515, Bela Vista, CEP: 13.506-900, Rio Claro, SP, Brasil. E-mail: didier. gastmans@unesp.br

José Luiz Albuquerque Filho - Instituto de Pesquisas Tecnológicas do Estado de São Paulo - IPT, Av. Prof. Almeida Prado, 532, Cidade Universitária, Butantã, CEP: 05508-901, São Paulo, SP, Brasil. E-mail: albuzelu@ipt.br

Vinícius Rosa Rodrigues e Julia Octaviano Noale - Departamento de Águas e Energia Elétrica - DAEE/ BMT/BMRC, Av. 16 BE, n 396, Bairro do Estádio, CEP: 13.501-330, Rio Claro, SP, Brasil. E-mails: vinicius.rodrigues@daee.sp.gov.br, julia.noale@daee.sp.gov.br

Andrea Segura Franzini - Serviço Geológico do Brasil - CPRM, Rua Costa, 55, Cerqueira César, CEP: 01304-010, São Paulo, SP, Brasil.E-mail: andrea.franzini@cprm.gov.br

Artigo recebido em 19 de maio de 2021, aceito em 22 de novembro de 2021. 